\title{
Púrpura Trombocitopênica Imunológica como Manifestação Inicial de Lúpus Eritematoso Sistêmico Juvenil(*)
}

\author{
Idiopathic Thrombocytopenic Purpura as Initial Manifestation \\ of Juvenile Systemic Lupus Erythematosus
}

\author{
Josefina Aparecida Pellegrini Braga ${ }^{(1)}$, Mary Hokazono ${ }^{(2)}$, Maria Teresa R. A. Terreri( ${ }^{(3)}$ e Maria Odete E. Hilário ${ }^{(4)}$
}

\section{RESUMO}

Os pacientes com púrpura trombocitopênica imunológica apresentam risco aumentado para desenvolver lúpus eritematoso sistêmico, principalmente quando a doença evolui de forma crônica. Alguns autores observaram que o sexo feminino, a idade mais avançada, a história familiar para lúpus eritematoso sistêmico podem ser fatores indicadores de maior risco para desenvolver lúpus em pacientes com púrpura trombocitopênica imunológica. Com base nestes fatos, resolvemos estudar cinco crianças nas quais a púrpura trombocitopênica imunológica foi o primeiro sintoma do lúpus eritematoso sistêmico. Neste artigo descrevemos as características clínicas e laboratoriais de cinco crianças com púrpura trombocitopênica imunológica que desenvolveram lúpus eritematoso sistêmico juvenil. Todas as crianças eram do sexo feminino - três caucasóides e duas pardas, com idade do início das manifestações de PTI variando entre 6 anos e 3 meses a 12 anos e 1 mês (média de 9 anos e 2 meses). A idade do diagnóstico de LESJ variou de 8 a 13 anos e 8 meses (média de 10 anos e 10 meses). Portanto, o intervalo de tempo entre o quadro de PTI e o diagnóstico de LESJ foi de 11 meses a 2 anos e 9meses (média de 1 ano e 10 meses). Todas as crianças apresentavam quadro de PTI crônica (plaquetopenia por mais de 6 meses). Os critérios de classificação para LESJ foram, em ordem de freqüência: rash malar e FAN positivo em 5 pacientes; artrite, alterações hematológica (plaquetopenia) e imunológica (anticorpo anti-DNA nativo) em 4; fotossensibilidade e ACL positivo em 3. Outras manifestações associadas foram úlceras orais, alterações renal e hematológica (leucopenia e AHAI com TCD positivo); serosite (pericardite), acometimento neurológico e alteração imunológica (anticorpo anti-Sm). Gostaríamos de alertar para esta forma de apresentação do lúpus eritematoso sistêmico

\begin{abstract}
Patients with Idiopathic Thrombocytopenic Purpura (ITP) present a high trend to develop Systemic Lupus Erythematosus (SLE), especially those with chronic presentation. Some authors observed that female gender, older patients and familial history of autoimmune disease in patients with Idiopathic Thrombocytopenic Purpura are factors that lead to increased susceptibility for the development of Systemic Lupus Erythematosus. Based on these facts, we decided to study 5 children with chronic Idiopathic Thrombocytopenic Purpura and late Systemic Lupus Erythematosus. In this paper, we describe the clinical and laboratorial features of 5 female children with Idiopathic Thrombocytopenic Purpura that later developed Systemic Lupus Erythematosus. All patients were girls, 3 Caucasian, with Idiopathic Thrombocytopenic Purpura onset age ranged between 6 years and 3 months and 12 years and 1 month (mean 9 years and 2 months). The age at Systemic Lupus Erythematosus diagnosis ranged between 8 years and 13 years and 8 months (mean - 10 years and 10 months). Though, the gap between Idiopathic Thrombocytopenic Purpura and Systemic Lupus Erythematosus diagnosis ranged between 11 months and 2 years and 9 months (mean - 1 year and 10 months). All patients presented chronic Idiopathic Thrombocytopenic Purpura (thrombocytopenia lasts longer than 6 months). The Systemic Lupus Erythematosus classification criteria were (in decreasing frequency): malar erythema and positivity of ANA in 5 patients; arthritis, hematological (thrombocytopenia) and immunological alterations (positivity of anti-DNA) in 4 patients; photosensitivity and positivity of anticardiolipin in 3 patients. Other manifestations included oral ulcers, renal involvement, leukopenia and auto-immune hemolytic anemia, serositis (pericarditis), neurological involvement and positivity of anti-Sm antibody. We would like to emphasize this form of
\end{abstract}

\footnotetext{
Departamento de Pediatria da Universidade Federal de São Paulo - Escola Paulista de Medicina. Recebido em 27/02/2003. Aprovado, após revisão, em 18/07/2003. . Professora Adjunta da Disciplina de Especialidades Pediátricas e responsável pelo setor de Hematologia Pediátrica da UNIFESP/EPM.

2. Médica Pediatra, com especialização em Hematologia Pediátrica.

. Professora Assistente da Disciplina de Alergia, Imunologia Clínica e Reumatologia da UNIFESP/EPM.

4. Professora Livre-Docente da Disciplina de Alergia, Imunologia Clínica e Reumatologia da UNIFESP/EPM.
} 
em que o primeiro sintoma foi a púrpura trombocitopênica imunológica e salientar a importância da determinação de autoanticorpos para lúpus eritematoso sistêmico nas crianças com a forma crônica desta patologia.

Palavras-chave: púrpura trombocitopênica imunológica, lúpus eritematoso sistêmico, plaquetopenia, anticardiolipina, crianças.

\section{INTRODUÇÃO}

A púrpura trombocitopênica imunológica (PTI) é definida como uma doença auto-imune caracterizada por clearance aumentado de plaquetas, causado por auto-anticorpos antiplaquetários, os quais se ligam às plaquetas circulantes, resultando na sua destruição pelo sistema reticuloendotelial ${ }^{(1)}$.

Clinicamente a PTI caracteriza-se por início abrupto de equimoses e petéquias, sangramentos mucosos ativos como epistaxe, gengivorragia, hematúria e sangramento gastrointestinal, além de hemorragia intracraniana (principal causa de mortalidade) ${ }^{(1,2)}$.

$\mathrm{Na}$ história, é freqüente relato de infecção viral ou imunização uma a três semanas antes da apresentação inicial da $\operatorname{PTI}^{(1,3)}$.

A PTI infantil é uma doença, em geral, aguda, autolimitada, com remissão espontânea, em torno de 90\% em seis meses, independentemente de tratamento ${ }^{(3,4)}$. Ao redor de $10 \%$ a 20\% dos casos de PTI aguda evoluem de forma crônica, com persistência ou recorrência de trombocitopenia abaixo de $150.000 / \mathrm{mm}^{3}$, por mais de seis meses ${ }^{(4)}$, um curso clínico mais parecido com o observado em adultos ${ }^{(3-5)}$. Nesses casos remissão espontânea ocorre em proporção muito menor ${ }^{(4)}$.

$\mathrm{Na}$ literatura tem sido descrito um risco aumentado dos pacientes com PTI de desenvolver lúpus eritematoso sistêmico (LES), principalmente quando a PTI evolui de forma crônica. Segundo alguns autores, cerca de $1 \%$ a $23 \%$ dos pacientes com PTI, durante sua evolução, apresentam critérios diagnósticos para $\mathrm{LES}^{(6-8)}$.

Em relação ao LES, 3\% a 16\% dos pacientes lúpicos têm diagnóstico de PTI precedendo o quadro ${ }^{(8,9,10)}$.

Alguns autores observaram que o sexo feminino, a idade mais avançada, a história familiar positiva para LES e a menor freqüência de infecções virais podem ser fatores indicadores de maior risco de evolução para LES em pacientes com PTI ${ }^{(3,6,7)}$.

Anticorpo antinúcleo (FAN) tem sido demonstrado no soro de alguns pacientes com PTI, mas é provável que somente os altos títulos ou a presença de anticorpo antiDNA, tenha valor preditivo para a evolução para $\operatorname{LES}^{(6,7)}$. presentation of Systemic Lupus Erythematosus, in which the Idiopathic Thrombocytopenic Purpura was the first manifestation and that the auto-antibody determination in every children with chronic form of this disease is very important.

Keywords: idiopathic thrombocytopenic purpura, systemic lupus erythematosus, thrombocytopenia, cardiolipin antibody, children.

O intervalo de tempo entre a PTI e o LES pode variar de meses a anos (8 meses a 4 anos) $)^{(6,8)}$.

Neste artigo descrevemos as características clínicas e laboratoriais de cinco crianças com PTI que desenvolveram lúpus eritematoso sistêmico juvenil (LESJ).

\section{RELATO DE CASOS}

Descrevemos cinco casos clínicos de crianças com PTI crônica (plaquetopenia por mais de 6 meses) que desenvolveram LESJ acompanhadas no setor de Reumatologia Pediátrica no período de 1990 a 2001. Os dois primeiros casos foram provenientes do Setor de Hematologia Pediátrica de nosso serviço e os demais casos de serviços externos. A Tabela 1 mostra as características demográficas, clínicas e laboratoriais dos pacientes.

\section{CASO 1}

Paciente caucasóide, sexo feminino, referiu manifestações de PTI com 9 anos e 9 meses. Ao exame laboratorial apresentava 9.000 plaquetas, sem hematúria, e testes de Coombs direto (TCD) e indireto (TCI) negativos. O mielograma apresentou hiperplasia megacariocítica e o fundo de olho estava sem sinais de sangramento. Foi iniciada pulsoterapia com metilprednisolona ( $30 \mathrm{mg} / \mathrm{kg} /$ dose) seguida de prednisona $(1 \mathrm{mg} / \mathrm{kg} / \mathrm{dia})$ durante quatro semanas com normalização plaquetária. O paciente apresentou várias recidivas após um mês de suspensão do corticóide. Foi realizado também tratamento com imunoglobulina humana endovenosa (Ig, IV) na dose de $2 \mathrm{~g} / \mathrm{kg}$, com resposta parcial, havendo necessidade de novas pulsoterapias, demonstrando corticodependência. Após cinco meses evoluiu com artrite de grandes articulações, mantendo a plaquetopenia e FAN positivo com padrão pontilhado fino, anti-DNA negativo e anticorpo anticardiolipina (ACL) IgG positivo e IgM negativo. Após seis meses do início da artrite, apresentou rash malar e fotossensibilidade, tendo sido feito diagnóstico de LESJ (aos 10 anos e 8 meses). Nessa época foi prescrita ciclosporina ( $5 \mathrm{mg} / \mathrm{kg} / \mathrm{dia}$ ) com boa resposta, da qual ainda 
faz uso. Apresentou positividade do TCD e TCI após seis meses do diagnóstico de LES. Houve necessidade de Ig, IV, em duas ocasiões. Atualmente está sem corticoterapia. Na última consulta apresentou hemoglobina $(\mathrm{Hb})$ de 9,3 g/dL com persistência do TCD e TCI positivo em baixa titulação.

\section{CASO 2}

Paciente caucasóide, sexo feminino, iniciou manifestações de PTI aos 7 anos, tratada com pulsoterapia de metilprednisolona (30 mg/kg/dose) e corticóide oral (1 mg/kg/dia). Com 8 anos e 8 meses apresentou pericardite, rash malar, fotossensibilidade e anemia hemolítica auto-imune (AHAI) com TCD e TCI positivos. Teve poliartrite aos 9 anos e 5 meses; alopécia, leucopenia e vasculite com 9 anos e 9 meses. O diagnóstico de LESJ foi estabelecido quando admitida em nosso serviço, 2 anos e 9 meses após o diagnóstico inicial de PTI. Ao exame laboratorial apresentava $\mathrm{Hb}$ 5,6 g/dL; hematócrito (Htc) 19\%; leucócitos 2.900/ $\mathrm{mm}^{3}$ (7/29/1/62/1); plaquetas 20.000/ $\mathrm{mm}^{3}$; FAN (padrão homogêneo periférico) e anti-DNA positivos, CH50 diminuído (34\%) e ACL negativo. Foi iniciada pulsoterapia com metilprednisolona e prescrito corticóide oral e azatioprina (1 mg/kg/dia). Após 11 meses apresentou gengivorragia importante e hematúria, tendo sido necessária pulsoterapia com ciclofosfamida $\left(500 \mathrm{mg} / \mathrm{m}^{2}\right.$ até $\left.1 \mathrm{~g} / \mathrm{m}^{2}\right)$ e Ig IV $(2 \mathrm{~g} / \mathrm{kg})$ com melhora (12 e 15 infusões respectivamente). Evoluiu com plaquetopenia severa e infecção (septicemia por Enterobacter sp.), vindo a falecer após três anos do diagnóstico de LES.

\section{CASO 3}

Paciente caucasóide, sexo feminino, teve o início das manifestações de PTI com 12 anos e 1 mês, tratada com corticóide oral (1 mg/kg/dia). Aos 13 anos e 8 meses apresentou rash malar, vasculite, fenômeno de Raynaud, artrite e úlceras orais, tendo sido feito diagnóstico de LESJ após 1 ano e 7 meses do diagnóstico de PTI inicial. Ao exame laboratorial mantinha plaquetopenia de $92.000 / \mathrm{mm}^{3}$, leucócitos $4.400 / \mathrm{mm}^{3}$ (diferencial 0/57/1/0/36/6), TCD e TCI negativos, FAN (padrão homogêneo e periférico), anti-DNA e ACL positivos, sem alterações urinárias. Recebeu pulsoterapia com metilprednisolona (30 mg/kg/dose) durante nove meses e corticóide oral. Atualmente está em uso de hidroxicloroquina (5 mg/kg/dia), ciclosporina (5 mg/kg/dia) e pulsoterapia bimestral com metilprednisolona, apresentando normalização das plaquetas e negativação do anti-DNA.

TABELA 1

CARACTERÍSTICAS DEMOGRÁFICAS, CLÍNICAS E LABORATORIAIS DOS PACIENTES COM LÚPUS ERITEMATOSO SISTÊMICO JUVENIL PRECEDIDO POR PÚRPURA TROMBOCITOPÊNICA IMUNOLÓGICA $(\mathrm{N}=5)$

\begin{tabular}{|c|c|c|c|c|c|}
\hline Pacientes & 1 & 2 & 3 & 4 & 5 \\
\hline Sexo & $\mathrm{F}$ & $\mathrm{F}$ & $\mathrm{F}$ & $\mathrm{F}$ & $\mathrm{F}$ \\
\hline Raça & C & C & C & $P$ & $\mathrm{P}$ \\
\hline Idade PTI & $9 a 9 m$ & $7 a$ & $12 \mathrm{a} 1 \mathrm{~m}$ & $6 a 3 m$ & $8 a$ \\
\hline Idade LESJ & $10 a 8 m$ & $9 a 9 m$ & $13 a 8 m$ & $8 a$ & $10 a$ \\
\hline$\Delta \mathrm{t}$ PTI/LESJ & $11 \mathrm{~m}$ & $2 a 9 m$ & $1 \mathrm{a} 7 \mathrm{~m}$ & $1 a 9 m$ & $2 a$ \\
\hline Rash malar & + & + & + & + & + \\
\hline Fotossensibilidade & + & + & - & - & + \\
\hline Úlceras orais & - & - & + & + & - \\
\hline Artrite & + & + & + & + & - \\
\hline Serosite & - & + & - & - & - \\
\hline Alteração renal & - & - & - & + & + \\
\hline Trombocitopenia & + & + & + & - & + \\
\hline AHAI & + & + & - & - & - \\
\hline Leucopenia & - & + & - & - & - \\
\hline FAN & + & + & + & + & + \\
\hline Anti-DNA & - & + & + & + & + \\
\hline Anti-Sm & - & - & - & + & - \\
\hline $\mathrm{ACL}$ & + & - & + & - & + \\
\hline
\end{tabular}

$\mathrm{F}=$ feminino; $\mathrm{C}$ = caucasóide; $\mathrm{P}=$ parda; $\mathrm{PTI}$ = púrpura trombocitopênica imunológica; LESJ = lúpus eritematoso sistêmico juvenil; AHAI = anemia hemolítica auto-imune; $\mathrm{FAN}=$ anticorpo antinúcleo; $\mathrm{ACL}=$ anticorpo anticardiolipina. 


\section{CASO 4}

Paciente parda, sexo feminino, iniciou manifestações de PTI com 6 anos e 3 meses, tendo sido tratada com corticóide oral $(1 \mathrm{mg} / \mathrm{kg} / \mathrm{dia})$ durante um ano e meio, com redução gradual até suspensão do medicamento em virtude da melhora da plaquetopenia. Com 8 anos, apresentou artrite, febre, úlceras orais, vasculite em palato, fenômeno de Raynaud, rash malar e hipertensão arterial, tendo sido diagnosticado LESJ. Ao exame laboratorial estava com hemograma normal, FAN (padrão pontilhado grosso) e anti-DNA positivos, complemento indetectável, anti-Sm e anti-RNP positivos, ACL negativo, TCD e TCI negativos e proteinúria de $21 \mathrm{mg} / \mathrm{kg} / \mathrm{dia}$. Foram introduzidos corticóide oral, hidroxicloroquina $(5 \mathrm{mg} /$ $\mathrm{kg} / \mathrm{dia})$ e metotrexato (MTX) $(0,4 \mathrm{mg} / \mathrm{kg} / \mathrm{semana})$, além de anti-hipertensivos. Aos 12 anos evoluiu com hepatotoxicidade, sendo suspenso MTX e introduzida azatioprina (1 mg/kg/dia) com melhora da proteinúria. Após três anos evoluiu com vasculite importante, linfopenia e hipocomplementenemia, tendo sido introduzida pulsoterapia com metilprednisolona (30 mg/ $\mathrm{kg} /$ dose) com melhora acentuada. Atualmente, com 18 anos, faz acompanhamento na reumatologia clínica.

\section{CASO 5}

Paciente parda, sexo feminino, iniciou manifestações de PTI com 8 anos, tendo sido tratada com corticóide oral (1 mg/kg/dia), apresentando corticodependência. Após dois anos evoluiu com rash malar e fotossensibilidade, artralgia, edema palpebral, com evolução para insuficiência renal, tendo sido diagnosticado LESJ. Ao exame laboratorial apresentava $\mathrm{Hb} 8 \mathrm{~g} / \mathrm{dl}$, Htc 26\%, leucograma normal, plaquetas $47.000 / \mathrm{mm}^{3}$, TCD e TCI negativos, FAN (pontilhado fino), anti-DNA e ACL positivos, complemento indetectável, creatinina 2,9 e urina I sem alterações. Foi prescrita pulsoterapia com metilprednisolona (30 mg/kg/dose), hidroxicloroquina ( $5 \mathrm{mg} / \mathrm{kg} / \mathrm{dia})$, MTX ( $0,4 \mathrm{mg} / \mathrm{kg} / \mathrm{semana})$ e corticóide oral com melhora clínica e normalização das plaquetas e da função renal. Após um ano evoluiu com vasculite necrosante de coxas, acidente vascular cerebral (AVC), encefalopatia hipertensiva, proteinúria importante $(43 \mathrm{mg} / \mathrm{kg} / \mathrm{dia})$ e insuficiência renal. Foi introduzida pulsoterapia com ciclofosfamida $(500 \mathrm{mg} /$ $\mathrm{m}^{2}$ até $\left.1 \mathrm{~g} / \mathrm{m}^{2}\right)$, azatioprina $(1 \mathrm{mg} / \mathrm{kg} /$ dia $)$ e anticoagulação. Após quatro anos apresentou novo AVC com convulsão. Atualmente, com seqüela motora discreta, está em uso de ciclofosfamida e anticoagulação.

\section{DISCUSSÃO}

Têm sido descritos na literatura casos de crianças com PTI que evoluem de forma crônica e posteriormente desenvolvem $\operatorname{LESJ}^{(7,8,11,12)}$.

Os nossos cinco pacientes descritos eram do sexo feminino, predominância também encontrada na literatura nos casos de PTI crônica e LES $^{(3)}$. O intervalo médio de tempo entre as duas patologias foi de 1 ano e 10 meses. Nos trabalhos de literatura este intervalo pode variar de poucos meses a vários anos ${ }^{(6,8)}$.

A evolução da plaquetopenia inicial é extremamente variável. Nas nossas pacientes o número de plaquetas normalizou antes do diagnóstico de LES em 1 paciente; após o diagnóstico em 3 e manteve-se diminuído em 1 paciente.

Quanto às outras manifestações do LESJ, as mais comuns foram as manifestações cutâneas como rash malar e fotossensibilidade e articulares, além das alterações hematológica e/ou imunológica. Outros autores descrevem a apresentação do LES após PTI com manifestações clínicas variadas, observando também maior freqüência de manifestações cutâneas, articulares e anemia hemolítica ${ }^{(11,12)}$.

O LES é uma causa comum de PTI secundária, uma vez que os pacientes podem apresentar anticorpos contra plaquetas. Os anticorpos anticardiolipina (ACL) podem ser parcialmente responsáveis pela plaquetopenia relacionada ao lúpus, em decorrência dos anticorpos contra fosfolípide na membrana da plaqueta ${ }^{(13)}$. Três das nossas pacientes apresentavam ACL.

Como a taxa de ocorrência de LES em pacientes com apresentação inicial de PTI varia de $1 \%$ a $23 \%{ }^{(5,8)}$, vários autores defendem a idéia de se realizar uma triagem para detecção de auto-anticorpos para LES em todos os pacientes com PTI, especialmente naqueles do sexo feminino e com a forma crônica da doenç ${ }^{(6,7)}$. Entretanto, existem pacientes com PTI e positividade para FAN que não irão preencher ou só posteriormente preencherão os critérios para $\mathrm{LES}^{(14)}$.

A presença de anti-DNA, anti-Ro e ACL tem maior valor preditivo para o desenvolvimento de $\mathrm{LES}^{(6,14)}$, devendo estes auto-anticorpos serem pesquisados rotineiramente nos pacientes com PTI crônica. A sua positividade, associada ao quadro clínico, confirma o diagnóstico de LES; a positividade na falta de manifestação clínica determina a necessidade de observação rigorosa quanto ao aparecimento de sinais e sintomas de LES.

$\mathrm{Na}$ literatura é descrito que os pacientes com anemia hemolítica e plaquetopenia associadas ao LES podem ter um curso mais benigno do que os outros pacientes ${ }^{(15)}$. Em nossa 
casuística tivemos apenas um óbito (caso 2), que apresentava essas duas manifestações hematológicas e evoluiu com plaquetopenia grave e infecção até o êxito letal.

Alguns autores observaram que o sexo feminino e a idade mais avançada de início da doença podem ser fatores indicadores de maior risco de desenvolvimento de LES em pacientes com $\mathrm{PTI}^{(3,7)}$. Isto também foi observado em nossos pacientes, pois o predomínio do sexo feminino foi maior naqueles que desenvolveram LES do que nos restantes 57 pacientes com PTI acompanhados no serviço (100\% e 47\%,

\section{REFERÊNCIAS}

1. Waters AH. Autoimmune thrombocytopenia: clinical aspects. Semin Hematol 1992;229(1):18-25.

2. Lilleyman JS. Intracranial haemorrhage in idiopathic thrombocytopenic purpura: Paediatric Haematology Forum of the British Society for Haemathology. Arch Dis Child 1994;71:251-3.

3. Lusher JM and Zuelzer WW. Idiopathic thrombocytopenic purpura in childhood. Medical Progress 1966;68(6):971-9.

4. Walker RW and Walker W. Idiopathic thrombocytopenia, initial illness and long term follow up. Arch Dis Child 1984;59:316-22.

5. Stasi R, Stipa E, Masi M, et al. Long-term observation of 208 adults with chronic idiopathic thrombocytopenic purpura. Am J Med 1995;98:436-42.

6. Anderson MJ, Peebles CL, McMillan R and Curd JG. Fluorescent antinuclear antibodies and anti-SS-A/Ro in patients with immune thrombocytopenia subsequently developing systemic lupus erythematosus. Ann Intern Med 1985;103(4):548-50.

7. Zimmerman SA and Ware RE. Clinical significance of the antinuclear antibody test in selected children with idiopathic thrombocytopenic purpura. J Pediatr Hematol/Oncol 1997; 19(4):297-303.

8. Mestanza-Peralta M, Ariza-Ariza R, Cardiel MH and Alcocer-Varela J. Thrombocytopenic purpura as a initial manifestation of systemic lupus erythematosus. J Rheumatol 1997;24(5): 867-70. respectivamente) e a idade do início dos sintomas foi mais avançada no primeiro do que no segundo grupo (média de 9 anos e 2 meses e 5 anos, respectivamente).

Em resumo, gostaríamos de alertar para esta forma de LES em que o primeiro sintoma foi a PTI, aconselhando para que seja realizada a determinação de auto-anticorpos para LES nas crianças com PTI, especialmente naquelas do sexo feminino e com a forma crônica. A detecção precoce do LES pode permitir uma terapia imunossupressora específica, levando a melhor prognóstico.

9. Karpatkin S. Autoimmune thrombocytopenic purpura. Review. Blood 1980;56(3):329-43

10. Lawrence J, Wong JE and Nachman R. The cellular hematology of systemic lupus erythematosus. In: Lahita RG, ed. Systemic lupus erythematosus. New York: Churchill Livingstone; 1992. p.771.

11. Hepburn MJ, English JC and Keeling JH. Autoimmune idiopathic thrombocytopenic purpura with the subsequent occurrence of systemic lupus erythematosus. Cutis 1997;60(4):185-7.

12. Mitra S, Marwaha N, Marwaha RK, Trehan A and Sehgal S. Immune thrombocytopenic purpura with multiple auto-antibody: evolution into systemic lupus erythematosus. Case reports. Indian pediatrics 2000;37:197-200.

13. Asherson RA, Baguley E, Pal C and Hughes GRV. Antiphospholipid syndrome: 5 year follow up. Ann Rheum Dis 1991; 50:805-10

14. Panzer S, Penner E, Graninger W, Schulz E and Smolen JS. Antinuclear antibodies in patients with chronic idiopathic autoimmune thrombocytopenia followed 2-30 years. Am J Hematol 1989;32:100-3

15. Alger M, Alarcon-Segovia D and Rivero SJ. Hemolytic anemia and thrombocytopenic purpura: two related subsets of systemic lupus erythematosus. J Rheumatol 1977;4(4):351-7. 